\title{
A RELAÇÃO TRABALHO E EDUCAÇÃO NA REPRODUÇÃO DAS CONDIÇÕES DE PRODUÇÃO E DAS RELAÇÕES DE PRODUÇÃO
}

Marcos Cassin ${ }^{\mathrm{i}}$

\author{
Monica Fernanda Botiglierii
}

\begin{abstract}
RESUMO:
O texto pontua as relações entre Trabalho e Educação nas transformações históricas da organização do trabalho e as exigências desta na organização da educação para o trabalho e para a manutenção das relações de produção e a partir dessas referências faz-se algumas considerações desta relação, Trabalho e Educação, nas transformações no processo produtivo no interior no modo de produção capitalista na segunda metade do século XX, o que foi denominado por muitos de revolução técnico-científica. A partir desse percurso defende-se a tese da educação como importante elemento de reprodução das condições de produção, qualificação para o trabalho, e reprodução das relações de produção, processo persuasivo de legitimação das relações de produção dominantes numa determinada formação social. Por último afirmamos que o Estado nas sociedades de classes é mediador na relação Trabalho e Educação com o objetivo de reproduzir as condições de produção e as relações de produção.
\end{abstract}

Palavras-chave: Trabalho, Educação, Reprodução, Condições de produção, Relações de produção

\section{THE RELATIONSHIP WORK AND EDUCATION OF TERMS OF PRODUCTION AND RELATIONS OF PRODUCTION}

\begin{abstract}
:
The text points the relationship between work and education in historical transformations of work organization and the requirements of the organization of education for work and for the maintenance of relations of production and from those references is a few considerations of this relationship, Work and Education in changes in the production process within the capitalist mode of production in the second half of the twentieth century, which was called by many of scientific-technical revolution. From this route it supports the thesis of education as an important element of reproduction of production conditions, qualifications for the job, and reproduction of relations of production, persuasive process of legitimation of relations of production dominant in a particular social formation. Finally we affirm that the state in societies of classes is mediating the relationship work and education in order to reproduce the conditions of production and relations of production.
\end{abstract}

Key-words: Work, Education, reproduction, conditions of production, relations of production

\section{A relação Trabalho, Educação e Modo de produção}

A capacidade de dominação sobre a natureza é o que diferencia homens de animais. Ao contrário dos últimos, sujeitos às condições ambientais de sobrevivência, o homem em certo momento viu-se capaz de construir instrumentos e utilizá-los no atendimento de suas necessidades de alimentação, abrigo, etc., o que lhe possibilitou o domínio de seu meio, 
bem como seu desenvolvimento físico e psíquico, distanciando-o consideravelmente daqueles que até então lhe eram muito semelhantes. A esta ação que propiciou tal realidade denominou-se Trabalho.

Assim, para produzir o necessário a sua sobrevivência o homem trabalha e, para tanto, faz uso dos chamados meios de produção, estes por sua vez formados pelas ferramentas, ou instrumentos de trabalho e pela matéria a se constituir em produto, ou objeto de trabalho. A este conjunto, somada a força de trabalho, deu-se o nome de forças produtivas e, ao longo da história, tais forças têm se desenvolvido conforme o surgimento de novas necessidades e o que tem diferenciado um modo de produção daquele que o antecede ou o segue são as relações dos sujeitos com os meios de produção e entre si. Segundo Oliveira (1987),

Escravismo, feudalismo e capitalismo são formas sociais em que se tecem relações que dominam o processo de trabalho, a forma concreta do processo histórico, sob determinadas condições, que cria essas relações fundamentais. O processo histórico é compreendido, portanto, pela forma como os homens produzem os meios materiais, a riqueza. (1987, p.06).

Ao pensarmos acerca dos vários modos de produção e em particular as comunidades primitivas, nos deparamos com uma organização coletiva, onde meios de produção, assim como o produto do trabalho, são bens comuns e pertencem, portanto, a toda sociedade. Dado o baixo desenvolvimento das forças produtivas, não havia grande produção de excedentes, o que fazia com que o produto de um indivíduo fosse suficiente apenas para seu sustento, impossibilitando, até então, a exploração do homem pelo homem e constituindo, ainda neste momento, uma sociedade sem classes sociais.

Tal forma de organização do trabalho ia, ao decorrer da história, determinando a maneira como este grupo reproduzia suas condições e suas relações de produção. Durante este período a formação para o trabalho e ideológica ${ }^{\text {iii }}$ dos sujeitos dava-se muito mais de maneira espontaneísta, não sistematizada, pelo exemplo ocasionado principalmente pelo acompanhamento dos filhos aos seus pais durante o trabalho e na vida em comunidade e, desta maneira, todos produziam e usufruíam de seus esforços, produzindo e reproduzindo as condições de produção, assim como suas relações de produção, o que conheceu-se como comunista primitivo.

Diante do desenvolvimento da forças produtivas e de relações cada vez mais complexas, onde cresce o conhecimento sobre a produção de instrumentos, domesticação de animais, entre outros, desenvolvem-se instrumentos e relações que possibilitam a produção de excedentes, ou seja, a sociedade passa a produzir além do necessário para sua sobrevivência, figurativamente duas mãos passam a produzir o suficiente para alimentar mais de uma pessoa. Esse desenvolvimento das forças produtivas possibilita a organização de sociedades em que alguns homens trabalhem e outros se apropriem do trabalho daqueles, ou seja, a constituição de classes sociais, de homens proprietários e não proprietários dos meios de produção.

Esta nova organização da base econômica da sociedade determina, gradativamente, o surgimento da necessidade dos proprietários dos meios de produção em criarem mecanismos que legitimem a sua propriedade, bem como garantam sua apropriação sobre o trabalho e o produto daqueles não proprietários, tese que segundo Marx demonstra o aparecimento do Estado, instrumento da classe dominante para se manter enquanto tal, explorando e se apropriando do trabalho das classes dominadas. Assim, esta instituição utiliza-se de aparatos repressores, o uso da força e violência, a fim de afirmar sua dominação/exploração. O Estado no modo de produção escravista se constitui em 
instrumento de reprodução das condições de produção e reprodução das relações de produção escravistas.

Temos um cenário onde não mais são defendidos os interesses da coletividade, mas sim uma organização que se torna cada vez mais complexa e estratificada, a fim de atender àqueles que não necessariamente produzem, mas que se apropriam do que é produzido.

Grécia e Roma são exemplos clássicos de sociedades escravistas onde o papel do Estado enquanto a aparato político-ideológico se consolida como instrumento da classe dominante na legitimação de suas relações de dominação e exploração. Nesse sentido, somos levados a retomar o conceito de Estado ampliado e a idéia de que este, a classe dominante se utiliza da persuasão e da repressão como instrumento de dominação. Portanto, o Estado é o conjunto de Aparatos Repressivos e Ideológicos da classe dominante.

A partir do aparecimento da sociedade dividida em classes sociais e do Estado, o trabalho passa a ser concebido ideologicamente como tarefa degradante, dos condenados, dos homens livres não cidadãos, dos escravos, de todos os segmentos sociais subalternos. Em contrapartida a classe dominante alheia a tal atividade, mas que se apropria do trabalho de outros, tem o ócio como virtude e dignificador do cidadão. Nessa perspectiva ideológica do trabalho, os Estados escravistas não poderiam organizar instituições de educação para o trabalho, portanto a formação do trabalhador se dava no local e no exercício do trabalho. Já quanto à educação da classe dominante, essa tinha como determinação, em última instância, a reprodução das relações de produção, e era, deste modo, voltada a filosofia, a retórica e a política, entre outras áreas do conhecimento, que cumpriam o papel de legitimar as relações de dominação e exploração no interior da classe dominante e em sua relação com as classes dominadas. Vale ressaltar que havia, no escravismo, certa dificuldade na penetração das idéias dominantes por meio da persuasão, o que tornava os aparatos repressores principais instrumentos na reprodução das relações de produção.

Citamos ainda a distinção acerca do papel da educação para os dois períodos até agora compreendidos, comunismo primitivo e escravismo, sobre o qual Ponce (2005) afirma:

No momento da história humana em que se efetua a transformação da sociedade comunista primitiva em sociedade dividida em classes, a educação tem como fins específicos a luta contra as tradições do comunismo tribal, a inculcação da idéia de que as classes dominantes só pretendem assegurar a vida das dominadas, e a vigilância atenta para extirpar e corrigir qualquer movimento de protesto da parte dos oprimidos.

O ideal pedagógico já não pode ser o mesmo para todos; não só as classes dominantes têm ideais muito distintos dos da classe dominada, como ainda tentam fazer com que a massa laboriosa aceite essa desigualdade de educação como uma desigualdade imposta pela natureza das coisas, uma desigualdade, portanto, contra a qual seria loucura rebelar-se. (2005, p. 36).

O fim do escravismo e o estabelecimento de uma nova formar de organização do trabalho, que adiante constituiu o modo de produção feudal, não modificaram a concepção ideológica do trabalho, ou seja, o trabalho é uma atividade dos não virtuosos, não é algo para os cléricos e nobres, portanto a educação não pode ser a mesma para os que trabalham e os que se apropriam do trabalho desses.

Segundo Oliveira (1987), 
O Feudalismo sugere fundamentalmente a persistência de formas de coerção direta muito variáveis, traduzidas pelo trabalho compulsório sob relações de dominação e de servidão. Essas relações se concretizam primordialmente no campo, onde o produtor direto não é proprietário da terra e trabalha para o senhor sob formas de dependência social e jurídica legitimadas pelo poder político. (1987, p.48)

O Feudalismo era marcado pela "autonomia" e certo "isolamento" dos feudos, espaços limitados onde uma determinada população produzia e mantinha suas relações de troca, etc. Havia a presença do senhor feudal que cedia terras para que os servos produzissem e retornassem parte de seu produto a ele. Merece destaque o papel da Igreja durante este período, isto porque era ela importante veículo de manutenção e legitimação das relações sociais e de produção, dado que se fixava enquanto instituição de empréstimo e crédito rural a senhores feudais (Ponce, 2005) e exercia cada vez maior influência sobre a economia, a política e a educação. Assim, os monastérios se constituíram enquanto "as primeiras "escolas" medievais" (Ponce, 2005, p. 91) e sua intenção não era a instrução, mas sim a lição para a conformidade, para o silenciar e a aceitação diante das doutrinas cristãs, tendo em vista que não era de interesse para o clero a discussão com a plebe, ao contrário, seu intuito era manter-se em posição de poder sem quaisquer obstáculos. Relembramos ainda, acerca da distinção entre a educação das massas, voltada para a conformidade e, no limite, para a preparação para a guerra e defesa do senhor feudal e a instrução dos filhos dos senhores, principalmente no interior dos conventos, voltada à formação para a gramática, entre outras.

Interessante destacarmos que no feudalismo a formação para o trabalho ainda se mantém fora das preocupações do Estado que representa o interesse das classes dominantes, ainda cultiva a idéia deste enquanto atividade degradante. Nesse sentido a formação dos trabalhadores do campo e das cidades se dava de forma espontânea ou organizada, assistemática ou sistemática, se dava sempre no local de trabalho e sobre responsabilidade dos trabalhadores.

Já a educação das classes dominantes, anteriormente citadas, tinha como determinação, em última instância, a reprodução das relações de produção feudal no interior das classes dominantes e das classes dominadas, mas com um poder de persuasão no interior dessas últimas que no escravismo não havia obtido êxito, isto resultado do papel que a igreja cumpriu na formação do homem medieval que diferentemente do escravismo é o aparato ideológico que predominou nos mecanismos de reprodução das relações de produção.

Saltando agora ao modo de produção que se segue, ou seja, o capitalista, iniciamos tais apontamentos lembrando, primeiramente, que sua inserção não se deu de maneira homogênea. Ao longo de alguns séculos o mundo assiste a decadência do modo de produção feudal, até que no século XIX quase que a totalidade dos estados europeus organizam o modo de produzir a partir de relações capitalistas. Dado o crescimento do mercantilismo e conseqüente emersão da burguesia, o "Estado moderno europeu" (Oliveira, 1987, p.65) torna-se cada vez mais absolutista e centralizador, voltado aos interesses da classe que ascende, estes tanto comerciantes, quanto industriais, etc. Expandem-se os mercados e cresce a produção manufatureira, até então limitada aos feudos e realizada em pequena escala, além do surgimento da construção naval, em consequiência da expansão comercial por meio das navegações.

É cada vez maior a insuficiência da produção feudal no atendimento às novas necessidades, agora não mais locais, mas mundiais, o que, mais tarde, acabará por 
ocasionar o que se chamou de Revolução Industrial, "caracterizada pela evolução tecnológica aplicada na produção e a conseqüente revolução nos processos de produção e nas relações sociais" (OLIVEIRA, 1987, p.75). Seu símbolo principal foi a introdução da máquina a vapor, em substituição a força motriz humana ou animal até então empregada, mas certamente suas transformações não aconteceram homogeneamente, nem tampouco pararam por aí, tendo em vista que aquele trabalhador, que no feudalismo era preso à terra e posteriormente viu-se livre, porém não possuidor dos meios para produzir, agora tem como única fonte de sobrevivência a venda de sua força de trabalho ao capitalista, o que a transforma em mercadoria, que é apropriada pelo burguês por meio do salário.

À burguesia, classe ascendente e já dominante, não cabe mais a educação religiosa, tão pouco aquela livresca, voltada principalmente à nobreza de outrora. Agora interessam muito mais os conhecimentos práticos, úteis às negociações burguesas e o trabalho passa a ter uma conotação positiva na sociedade, o trabalho deixa de ser degradante para se constituir elemento de virtuosidade, o trabalho salva o corpo e a alma dos homens ${ }^{\mathrm{iv}}$. Deste modo, o capitalismo não rompe com as relações entre os proprietários e não proprietários dos meios de produção e do Estado como instrumento de dominação e exploração dos primeiros sobre os últimos. Nessa perspectiva, conferimos ao longo da história as consequiências do modo como os homens se organizam para o trabalho e como nas sociedades de classes são priorizados sempre os interesses daqueles que detém a propriedade dos meios de produção, impondo-se ao conjunto da sociedade pela mediação do Estado.

Nesse texto não tivemos a pretensão de fazer um percurso exaustivo sobre história do trabalho ou da educação, mas sim apenas pontuar as relações entre Trabalho e Educação nas transformações históricas na organização do trabalho e as exigências destas na organização da educação para o trabalho e para a manutenção das relações de produção. A partir dessas referências, faremos ainda algumas considerações desta relação, Trabalho e Educação, nas transformações no processo produtivo no interior no modo de produção capitalista na segunda metade do século XX.

\section{A Relação Trabalho e Educação e as Transformações Produtivas na segunda metade do século XX}

Partindo ainda da concepção de trabalho enquanto "ação do homem que transforma os materiais dispostos pela natureza em riqueza e que fundamenta a vida humana" (CASSIN, 2008, p.02), é possível refletir acerca dos últimos cem anos enquanto um período fortemente dinâmico, cujas principais mudanças se refletiram, novamente, nos diferentes aspectos da vida, como economia, política e aquele que tem merecido aqui certo destaque, a educação ${ }^{v}$. Portanto, na intenção de demonstrar características de como os homens passaram a se organizar para o trabalho neste período e, em especial, na segunda metade do século $\mathrm{XX}$, retomaremos o que foi denominado por muitos de revolução técnico-científica, quando transformações nas indústrias, na microbiologia, nas telecomunicações, entre outros, configuraram uma nova realidade, de reestruturação produtiva. Ponderemos assim, a respeito de como estas e outras alterações apontadas anteriormente tem criado, ao longo da história, novas necessidades de organização e formação dos indivíduos.

Em meados dos anos quarenta tem início uma transformação na maneira de produzir, esta que passa gradativamente de uma produção industrializada, mecânica, a uma realidade onde as máquinas aprimoram-se e passam a ser controladas eletronicamente. Por volta dos anos setenta cresce a incorporação de novas tecnologias no mundo e no Brasil e, 
enquanto a realidade industrial, embora se tratando já de certa racionalização do trabalho, utiliza-se de grandes e rígidas estruturas, além de vasta mão de obra e dispêndio de tempo e energia, a incorporação de equipamentos técnico-eletrônicos de Controle Numérico Computadorizado (CNC), bem como a utilização de "sistemas CAD/CAM (Computer Aided design/Computer Aided Manufacturing) que permitem projetar e definir peças numa tela de computador e enviar as especificações diretamente às máquinas de CNC" (CASSIN, 2008, p.12), reduz gastos com trabalho humano e tornam a produção flexível às demandas do mercado e do capital. Tais mudanças se fazem sentir não só na aquisição de equipamentos, mas em grande medida no que compete às relações estabelecidas na fábrica, ou seja, na maneira de gerir as atividades. Novidades como o "Just in time", os "CCQ's" e o "Kanban", são primeiramente introduzidas nas empresas mais desenvolvidas, sendo o primeiro um controle do que é fabricado em diálogo direto com o setor de vendas da empresa, o que tem como resultado menor desperdício e produção somente do necessário, tendo em vista que só se produz aquilo que já está sob encomenda. Já os "CCQ's", dizem respeito à "Círculos de Controle de Qualidade",

(...) que "consiste na formação de pequenos grupos de trabalhadores - de 6 a 12 funcionários -, que se reúnem periodicamente para propor medidas de melhoria da produção. Essa estrutura caminha paralelamente à hierarquia da empresa. Os "circulistas" continuam subordinados às chefias, suas sugestões têm caráter indicativo e não há mudança do sistema de trabalho (...)" (BORGES, 1992, p.54),

ou seja, há um discurso por parte do patronato de uma espécie de "administração compartilhada", o que acaba por criar vínculos entre pequenos grupos de operários e a hierarquia da companhia, que absorve conhecimentos dos funcionários que não exercem cargos de liderança, aumentando sua produtividade e fazendo-os acreditar, por meio de premiações, bonificações e outros artifícios, na importância de sua "cooperação", afastando-os, na maioria das vezes, de lutas e reivindicações dos demais trabalhadores. Além desta, outra incorporação do mesmo período é o chamado "Kanban", que corresponde a um sinal (luminoso ou de outro tipo), por meio do qual a empresa dá ordens de produção e controla o ritmo da mesma. Segundo Borges (1992), o Kanban "faz com que o operário agregue funções de inspeção e supervisão - o que reduz o número de funcionários não envolvidos diretamente com a produção". Com intermédio destes e outros mecanismos, a relação dos trabalhadores com o trabalho se modifica e, tanto saberes quanto modos de organização têm seu controle transferido das mãos do operário para o domínio da máquina e do patrão, isso porque aumentam as maneiras de controle do quanto e o que se produz e o conhecimento passa a se encontrar muito mais nos softwares, programados para adaptarem-se às inúmeras exigências possíveis, tendo o trabalhador como "executor de tarefas" que deve estar constantemente atento ao funcionamento regular das máquinas, assim como aos comandos que vem "de cima", determinando sua velocidade de produção.

Vale lembrar que esta revolução tecnológica não surge isoladamente no contexto de reestruturação produtiva, mas que apresenta outros elementos enquanto pano de fundo, como o modelo gerencial criado em oposição à produção Fordista/Taylorista, implantado primeiramente nas empresas japonesas e denominado Toyotismo, este que por sua vez vem substituir as linhas de produção em série por ilhas de produção que necessitam de trabalhadores mais flexíveis, operários com capacidade de operar várias, novas, máquinas que exigem tarefas simples, o trabalhador se constitui em agente produtivo polivalente. 
Diante das inovações e incorporações citadas anteriormente, já não cabe ao sistema produtivo vigente o mesmo operário formado para atender ao início da industrialização, fortemente capacitado para trabalhos mecânicos, como aqueles ligados a ferramentaria, tornearia, prensa, etc., tendo em vista que os novos tipos de equipamentos colocam tais profissões na obsolescência, o que além de causar desemprego em grande escala, expõe muitos a pressão de formarem-se para atender as novas demandas, afetando diretamente na maneira como se organiza a educação. Neste momento, o capitalismo requer indivíduos muito mais "aptos" às relações pessoais, de convívio e "parcerias" com as empresas, além de demandar por funções distintas das braçais, na medida em que com a inserção das novas tecnologias cria-se a necessidade de operários competentes, por exemplo, na escrita e leitura da Língua Portuguesa, visando à compreensão dos mais diversos manuais e comandos dos novos equipamentos. Outra exigência desta nova configuração é aquela que vem a procura de indivíduos preparados para trabalhos de programação e manutenção de softwares, o que novamente distancia-se da "velha" formação que prepara para trabalhos mecânicos.

\section{Algumas Considerações}

Ante o quadro de reestruturação produtiva e da necessidade de uma adequação na qualificação dos trabalhadores para lidar com os novos métodos e novas máquinas, de uma formação mais geral em detrimento de uma formação mais técnica nessa nova etapa da organização do trabalho no modo de produção capitalista, além das inúmeras análises, estudos e pesquisa da relação Trabalho e Educação, desse novo contexto entendemos que algumas questões devem ser apresentadas, ou reapresentadas:

1 - A desqualificação do trabalho exige uma adequação da qualificação do trabalhador. Nosso argumento aqui é de que com as novas formas de organizar o trabalho e das incorporações de novas tecnologias no processo de trabalho há uma diminuição na exigência de qualificação técnica na maioria dos postos, lugares, na produção e o crescimento de uma qualificação menos técnica e mais "geral" dos agentes da produção, os trabalhadores. O que estamos argumentando é de que não há uma desqualificação do trabalhador com as novas tecnologias, ou seja, não há uma subtração do conhecimento do trabalhador, mas a necessidade desse trabalhador adquirir novos saberes para que sua força de trabalho seja uma mercadoria apropriada ao novo mercado de trabalho. Importante destacarmos que a necessidade do capital de uma nova qualificação dos trabalhadores não se refere apenas aos empregados para que esses possam operar os novos instrumentos de trabalho, mas a ex

igência de qualificar os trabalhadores desempregados para que estes cumpram o papel de exército de reserva da força de trabalho.

2 - A relação Trabalho e Educação é condição do homem. Tal afirmação pauta-se na idéia do trabalho enquanto intrínseco na constituição do homem como ser coletivo que organiza a produção dos bens necessários para sua sobrevivência e a educação, portanto, é elemento fundamental para a reprodução da força de trabalho, enquanto capacidade técnica de exercer o trabalho. Cabe destacar o salário como reprodutor da força de trabalho na sociedade capitalista e que, além de dar conta das condições materiais mínimas de sobrevivência do trabalhador e de sua família, tem que ser em parte destinado a educação do operário e de seus filhos para que esses se produzam e reproduzam como mercadoria para o mercado de trabalho.

3 - A educação é um importante elemento de reprodução das condições de produção, qualificação para o trabalho, e reprodução das relações de produção, processo persuasivo 
de legitimação das relações de produção dominantes numa determinada formação social. 4 - Nas sociedades divididas em classes sociais o Estado é mediador na relação Trabalho e Educação, organizando, ou não, a formação dos trabalhadores com o objetivo de reproduzir as condições de produção, mas sempre organiza a educação como reprodutora das relações de produção buscando justificar como legitimas as relações de dominação e exploração das classes dominantes. Aqui entendemos o Estado como instrumento da classe dominante para manter seus interesses subordinando as classes dominadas através de seus aparatos repressores e ideológicos de Estado.

Quanto ao último tópico é importante destacar que partimos da concepção de educação como meio e não como fim em si mesmo. Portanto, para nós a educação não é conservadora e nem transformadora, mas que nas sociedades de classes enquanto processo normatizado, regulamentado, institucionalizado pelo Estado ${ }^{\mathrm{vi}}$ com o objetivo de produzir e reproduzir as condições de produção e produzir e reproduzir as relações de produção a educação se constitui em instrumento da classe dominante para se perpetuar como classe dominante que explora e domina as classes subordinadas aos seus interesses.

\section{BIBLIOGRAFIA}

ALTHUSSER, Louis. Aparelhos Ideológicos de Estado. $3^{\text {a }}$ edição. Rio de Janeiro: Edições Graal, 1987. . Sobre a Reprodução. Petrópolis: Editora Vozes, 1999.

ANTUNES, Ricardo. Adeus ao Trabalho?. 5ª edição. São Paulo: Cortez, 1998. (org.). Riqueza e Miséria do Trabalho no Brasil. $1^{a}$ edição. São Paulo: Boitempo, 2006.

BORGES, Altamiro. Novidades na Exploração Dentro das Fábricas. Princípios, São Paulo, n.24, p. 50 - 56, Abril, 1992.

Efeitos da Microeletrônica no Mundo do Trabalho. Princípios, São

Paulo, nº.25, p. 54 - 60, Julho, 1992.

Reflexos da Automação na Consciência Operária. Princípios, São

Paulo, n'.26, p. 35 - 41, Outubro, 1992.

BRAVERMAN, Harry. Trabalho e Capital Monopolista. $3^{\text {a }}$ edição. Rio de Janeiro:

Editora Guanabara, 1987.

CASSIN, Marcos. Trabalho e Formação Humana. 2008, (mimeo).

ENGELS, Friedrich. O Papel do Trabalho na Transformação do Macaco em Homem I

OAKLEY, Kenneth B. O Homem Como Ser que Fabrica Utensílios. $2^{\mathrm{a}}$ edição. São Paulo: Global Editora, 1984.

HARNERCKER, Marta. Tornar Possível o Impossível. São Paulo: Paz e Terra, 2000.

LAFARGUE, Paul. O Direito à Preguiça. 2a edição. São Paulo: Editora Hucitec, 2000.

Revista HISTEDBR On-line, Campinas, n. Especial, p.112-120, mai.2009 - ISSN: 1676-2584 
OLIVEIRA, Carlos R. de. História do Trabalho. São Paulo: Editora Ática, 1987. (Série Princípios).

POUlantZAS, Nicos. As Classes Sociais no Capitalismo de Hoje. $2^{\mathrm{a}}$ edição. Rio de Janeiro: Zahar Editores, 1978.

WEBER, Max. A Ética Protestante e o "Espírito" do Capitalismo. São Paulo: Companhia das Letras, 2004.

\footnotetext{
i Professor de Sociologia da Educação do Departamento de Psicologia e Educação da Faculdade de Filosofia, Ciências e Letras da Universidade de São Paulo.

ii Pedagoga formada pela Faculdade de Filosofia, Ciências e Letras da Universidade de São Paulo.

iii $\mathrm{O}$ conceito de ideologia aqui está sendo usado como concepção de mundo.

iv Sobre esse aspecto indicamos as leituras de Max Weber "A ética protestante e o espírito do capitalismo" e o texto de Paul Lafargue "O direito a preguisa".

v Educação compreendida até então enquanto processos de formação do indivíduo, efetivados tanto dentro quanto fora de instituições formais de ensino.

${ }^{v i}$ Isto não significa que não haja contradições, resistências, processos de negação, mas que enquanto processo instituído pelo Estado a educação pública ou privada, em última instância, é reprodutora.
}

Artigo recebido em: 15/01/2009

Aprovado para publicação em: 30/01/2009 